\title{
The role of biogenic Fe-Mn oxides formed in situ for arsenic oxidation and adsorption in aquatic ecosystems
}

\author{
Yaohui Bai ${ }^{a}$, Tingting Yang ${ }^{a}$, Jinsong Liang ${ }^{\mathrm{a}, \mathrm{b}}$, Jiuhui $Q \mathrm{u}^{\mathrm{a}, *}$ \\ ${ }^{a}$ Key Laboratory of Drinking Water Science and Technology, Research Center for Eco-Environmental Sciences, Chinese Academy of Sciences, Beijing 100085, \\ China \\ ${ }^{\mathrm{b}}$ University of Chinese Academy of Sciences, Beijing 100049, China
}

\section{A R T I C L E I N F O}

\section{Article history:}

Received 12 November 2015

Received in revised form 23 March 2016

Accepted 29 March 2016

Available online 1 April 2016

\section{Keywords:}

Biogenic Mn oxide

Iron oxyhydroxide

Biogenic Fe-Mn oxides

Oxidation and adsorption

Arsenic

\begin{abstract}
A B S T R A C T
As(III\&V), Mn(II), and Fe(II) may occur simultaneously in some groundwater and surface water. Studying their redox reactions and interactions is essential to unravel the biogeochemical cycles of these metal ions in aquatic ecosystems and to find effective methods to remove them simultaneously in drinking water treatment. Here, the formation of biogenic Fe-Mn oxides (BFMO, defined as a mixture of biogenic $\mathrm{Mn}$ oxide (BMO) and Fe oxide) as well as its oxidation and adsorption of $\mathrm{As}$ in a $\mathrm{Fe}(\mathrm{II})-\mathrm{Mn}(\mathrm{II})-\mathrm{As}(\mathrm{III} \& \mathrm{~V})-$ Mn-oxidizing microbe (Pseudomonas sp. QJX-1) system were investigated. Batch experiments and structure characterization revealed that the BFMO was formed via a sequential precipitation of Fe oxide and BMO. The first formed Fe oxide was identified as $\mathrm{FeOOH}$ (lepidocrocite) and the latter formed BMO was identified as $\mathrm{MnO}_{2}$ (similar to hexagonal birnessite). In the BFMO mixture, the BMO part was mainly responsible for $\mathrm{As}(\mathrm{III})$ oxidation, and the Fe oxide part dominated As adsorption. Remarkably, the BMO could oxidize $\mathrm{Fe}(\mathrm{II})$ to form $\mathrm{FeOOH}$, which may improve As adsorption. The optimum $\mathrm{Mn}$ (II)/Fe(II) ratio for As removal was approximately 1:3 (mol/mol). Taken together, in Fe(II)-Mn(II)-As(III\&V)-Mn-oxidizing microbe ecosystems, the in situ formation of BFMO could eliminate or decrease $\mathrm{Fe}(\mathrm{II}), \mathrm{Mn}(\mathrm{II})$, and $\mathrm{As}(\mathrm{III} \& \mathrm{~V})$ species simultaneously. Therefore, based on this study, new approaches may be developed for As removal from water containing high concentrations of $\mathrm{Fe}(\mathrm{II})$ and $\mathrm{Mn}(\mathrm{II})$.
\end{abstract}

(c) 2016 Elsevier Ltd. All rights reserved.

\section{Introduction}

In groundwater and in some surface water, soluble Fe(II) and Mn(II) often occur together (Huang et al., 2012; Postawa and Hayes, 2013), and Fe and Mn oxides are produced by oxidative precipitation under aerated conditions. Fe oxide is mainly formed by $\mathrm{Fe}(\mathrm{II})$ chemical oxidation (Kappler and Straub, 2005), and Mn oxide is formed via biological Mn(II) oxidation. Accordingly, Fe-Mn oxides are often formed in situ in natural aquatic ecosystems as well as in groundwater treatment systems (Bai et al., 2013). Extensive studies have suggested that biogenic Mn oxide (BMO) is an efficient sorbent and oxidant due to its highly charged surface and oxidizing power (Hansel et al., 2011; Tebo et al., 2010); and synthetic Fe oxide is a powerful sorbent that is currently used in drinking water treatment processes (Faust, 1998). However, the oxidation and adsorption characteristics of the biogenic Fe-Mn oxides (defined as

\footnotetext{
* Corresponding author.

E-mail address: jhqu@rcees.ac.cn (J. Qu).
}

BMO combined with Fe oxide, BFMO) formed in situ remain largely unknown.

Arsenic (As) is a ubiquitous contaminant that jeopardizes water quality, and its trivalent species has higher toxic effects (Gebel, 1997). High concentrations of As are found in some surface water and groundwater along with high $\mathrm{Fe}(\mathrm{II})$ and $\mathrm{Mn}$ (II) concentrations, and all of these contaminants present a threat to public health and aquatic ecology (Davolos and Pietrangeli, 2013). For treatment, the desirable solution is to eliminate or decrease these three ions simultaneously from contaminated water. Based on this, some treatment methods/processes was developed, for example, aeration together with chlorination or ozonation followed by filtration can be used to remove $\mathrm{Fe}(\mathrm{II})$ and $\mathrm{Mn}(\mathrm{II})$, which would also remove As species (depending on the As/Fe ratio) (Nishimura and Umetsu, 2001). Greensand filters (Viraraghavan et al., 1999) and householdscale sand filters (Berg et al., 2006; Voegelin et al., 2014) have also been shown to remove them simultaneously. Here we provide another treatment concept, by means of strengthening the formation of BFMO in the treatment system. The following hypothesis based on the oxidation and adsorption properties of BMO (Murray 
et al., 2005; Wu et al., 2005) and Fe oxide (Fig. 1) was proposed: When a Mn-oxidizing microbe such as Pseudomonas sp. QJX-1 is introduced, soluble $\mathrm{Mn}$ (II) will be oxidized to insoluble $\mathrm{Mn}$ (IV) oxide (BMO), which will mix with insoluble Fe oxide produced from chemical Fe(II) oxidation in an aerated environment to form BFMO. The BFMO formed in situ will then oxidize and adsorb As species. It was assumed that BMO oxidize (and adsorb?) As and that Fe oxide adsorb As. Meanwhile, As oxidation may lead to the reduction of Mn oxide to $\mathrm{Mn}(\mathrm{II})$. However, $\mathrm{Mn}(\mathrm{II})$ will be reoxidized biologically to BMO. With this cycle, the Fe(II), Mn(II), and As(III\&V) species may be efficiently removed from the water.

In this study, the hypothesis was experimentally verified, and the valence shifts of $\mathrm{Fe}, \mathrm{Mn}$, and As during the reaction, the respective roles of $\mathrm{Mn}$ oxide and $\mathrm{Fe}$ oxide in As oxidation and adsorption, and the interaction between Fe oxide and Mn oxide were also clarified. Therefore, the findings from this study may not only shed light on the biogeochemical cycles of three elements in natural or engineered ecosystems but also may provide a new method to treat water containing $\mathrm{Mn}(\mathrm{II}), \mathrm{Fe}(\mathrm{II})$, and $\mathrm{As}(\mathrm{III} \& \mathrm{~V})$ species.

\section{Materials and methods}

\section{1. $M n(I I)$-oxidizing bacterial strain}

A Mn(II)-oxidizing bacterium was isolated from the soil of a Mn mine, located in Xiangtan City, Hunan Province, China. According to the physicochemical and 16S rRNA characterizations, the bacterium was identified and named as Pseudomonas sp. QJX-1 (GeneBank accession number, KM242057). QXJ-1 is a Gram-negative, rod strain with dimensions of $1-2.1 \mu \mathrm{m}$ in length and $0.5-0.9 \mu \mathrm{m}$ in width. A culture of the strain has been deposited in the China General Microorganism Culture Center (CGMCC; accession number, 6630).

\subsection{Enrichment of inoculated bacteria}

Peptone-yeast extract-glucose (PYG) medium, described by Adams and Ghiorse (1985), was modified slightly and used in the experiments. Each liter of PYG contained $0.25 \mathrm{~g}$ of peptone, $0.25 \mathrm{~g}$ of yeast extract, $0.25 \mathrm{~g}$ of glucose, $0.5 \mathrm{~g}$ of $\mathrm{MgSO}_{4} \cdot 7 \mathrm{H}_{2} \mathrm{O}$, and $0.06 \mathrm{~g}$ of $\mathrm{CaCl}_{2} \cdot 2 \mathrm{H}_{2} \mathrm{O}$. The pH of the PYG medium was adjusted to 7.5 with $1 \mathrm{M} \mathrm{NaOH}$ before autoclaving. Approximately $15 \mathrm{mM} \mathrm{N}-2-$ hydroxyethylpiperazine-N'-2-ethanesulfonic acid (HEPES) was used as the buffer in the PYG medium.

Pseudomonas sp. QJX-1 was inoculated in several 250-ml flasks containing $100 \mathrm{ml}$ of PYG media and incubated at $30{ }^{\circ} \mathrm{C}$ and

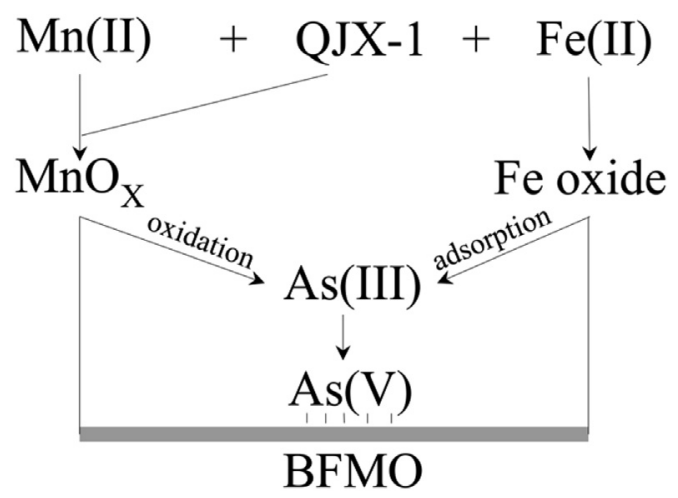

Fig. 1. The proposed hypothesis for the oxidation and adsorption of As(III) by BFMO formed in situ.
$170 \mathrm{rpm}$ in a rotary shaker until the bacteria reached the logarithmic phase of growth (approximately $48 \mathrm{~h}$ ). The bacterial suspensions were used immediately for the following oxidation and adsorption experiments.

\subsection{BFMO formation and its oxidation and absorption for As species}

First, BFMO formation and its removal of As with different initial $\mathrm{Mn} / \mathrm{Fe}$ ratios ( $\mathrm{mol} / \mathrm{mol}$ ) were investigated to determine the optimum ratio. The experiment used a series of 500-ml Erlenmeyer flasks as batch reactors. Each flask contained $200 \mathrm{ml}$ of PYG medium containing $100 \mu \mathrm{M} \mathrm{Mn}(\mathrm{II})$ (prepared with $\mathrm{MnCl}_{2}$ ), $10 \mu \mathrm{M}$ $\mathrm{As}\left(\mathrm{III} \& \mathrm{~V}\right.$, prepared with sodium arsenite $\left(\mathrm{NaAsO}_{2}\right)$ and sodium arsenate $\left(\mathrm{NaAsO}_{4} \cdot 12 \mathrm{H}_{2} \mathrm{O}\right)$, respectively), and different initial concentrations of $\mathrm{Fe}(\mathrm{II})$ (prepared with $\mathrm{FeSO}_{4} \cdot 7 \mathrm{H}_{2} \mathrm{O}$ ). The initial inoculum sample had an optical density at $600 \mathrm{~nm}$, corresponding to less than 0.1 units. Flasks without the bacterial inoculum were used as negative controls under the same conditions. All flasks were sealed with sealfilm and shaken at $30^{\circ} \mathrm{C}$ and $170 \mathrm{rpm}$. After $72 \mathrm{~h}$, at which time BFMO formation and As adsorption were complete, suspensions were sampled and filtered through a $0.22-\mu \mathrm{m}$ membrane for $\mathrm{Mn}(\mathrm{II}), \mathrm{Fe}(\mathrm{II}), \mathrm{As}(\mathrm{III}), \mathrm{As}(\mathrm{V})$, and total As determination. The $\mathrm{pH}$ values were measured at the beginning and at the end of the experiment.

According to the removal capacities of the BFMOs with different initial $\mathrm{Mn} / \mathrm{Fe}$ ratios, the optimum $\mathrm{Mn} / \mathrm{Fe}$ ratio was confirmed. To explore the oxidation and adsorption processes as well as the underlying mechanisms, the batch experiment for As oxidation and adsorption by the BFMO with the optimum Mn/Fe ratio was conducted. The oxidation and adsorption capacities of the BMO and Fe oxide, separately, were also tested and compared with those of the BFMO. Sampling was performed at regular intervals. The concentrations of $\mathrm{Fe}(\mathrm{II}), \mathrm{Mn}(\mathrm{II})$, and $\mathrm{As}(\mathrm{III} \& \mathrm{~V})$ as well as $\mathrm{pH}$ were analyzed.

\subsection{As, Fe and Mn species determination}

For soluble $\mathrm{Mn}(\mathrm{II})$, soluble $\mathrm{Fe}(\mathrm{II})$, total As concentration determination, the water samples were filtered through a $0.22-\mu \mathrm{m}$ membrane, adjusted to $\mathrm{pH}<2$ with $1 \mathrm{~mol} / 1 \mathrm{HCl}$, and then measured using an inductively coupled plasma/optical emission spectrometry (ICP-OES, Agilent 710 series). The $\mathrm{OD}_{600}$ was measured using a UV spectrophotometer (Hitachi U-3010). For As(III) concentration determination, the water samples were directly filtered through a $0.22-\mu \mathrm{m}$ membrane and then analyzed using an atomic fluorescence spectrometry (AF-610B, Beijing Rayleigh Analytical Instrument Co., China). As(V) concentration was calculated by subtracting the $\mathrm{As}(\mathrm{III})$ value from the total As concentration value.

\section{5. ऊ-Potential analysis and particle size}

ל-Potential analysis was performed to explore the surface charge variation during the formation of Fe oxide, BMO, and BFMO as well as the oxidation and adsorption of As species. Suspensions were prepared in the same way as for the batch sorption (oxidation) experiment samples, and aliquots were withdrawn and subjected to a $\zeta$-potential analyzer (DelsaNano C, Beckman Coulter, Inc., USA). Smoluchowski equation was used for the conversion of electrophoretic mobility into $\zeta$-potential. The average particle size was also measured using a dynamic light scattering system (Zetasizer Nano ZS, Malvern, UK) to observe the size variation in the formation processes of Fe oxide, BMO, and BFMO.

\subsection{Structural characterization}

Transmission electron microscope (TEM) and field emission 
scanning electron microscopy (FE-SEM) coupled with energydispersive X-ray analysis (EDX) were used to investigate the morphology, size, and element distribution of the BMO, Fe oxide, and BFMO. The media producing BMO, Fe oxide, and BFMO (described above) were incubated for $72 \mathrm{~h}$. Suspensions were collected, centrifuged $(5000 \times g)$ and washed twice with sterile Milli-Q water to remove the organic matters and salts in the media. Finally, the collected precipitates were resuspended in $1 \mathrm{ml}$ of Milli$\mathrm{Q}$ water. The samples were divided into two aliquots. One was mounted on double-sided carbon tape and sputter-coated with a $\mathrm{Pt} / \mathrm{Pd}$ film prior to imaging with a FE-SEM/EDX analyzer (Hitachi SU-8020). The other was imaged with a Hitachi H-7500 transmission electron microscope. For X-ray Powder Diffraction (XRD) analysis, BMO, Fe oxide and BFMO precipitates were collected by centrifugation of incubated suspensions (1-2L, $72 \mathrm{~h}$ ) and then dried with a freeze drier. The dried samples were grinded into powder using pestle and mortar. Finally the pressed powder disk was prepared and then analyzed using an X'Pert PRO MPD X-ray spectrometer (Netherlands) with $\mathrm{Cu}-\mathrm{K}\langle\mathrm{alpha}\rangle$ irradiation, PIXcel detector, generator voltage of $40 \mathrm{kV}$ and tube current of $40 \mathrm{~mA}$. The data were collected at a $0.71^{\circ} 2 \mathrm{Th} / \mathrm{min}$ of scanning speed in the angle range from $10^{\circ}$ to $80^{\circ}$ for $\mathrm{BMO}$, and from $5^{\circ}$ to $90^{\circ}$ for Fe oxide and BFMO.

To further understand the valence shifts of As, Fe, and Mn in the experiment as well as the coordination of As associated with the $\mathrm{BMO}$ and BFMO, the lyophilized powder pellets of BMO, Fe oxide, BFMO, and their As adsorption samples ( $72 \mathrm{~h}$ ) were analyzed at the Beijing Synchrotron Radiation Facility (BSRF), China, for X-ray absorption near-edge structure (XANES) and K-edge extended X-ray absorption fine structure (EXAFS) analyses. Eight reference compounds including $\mathrm{MnO}, \mathrm{Mn}_{2} \mathrm{O}_{3}, \mathrm{Mn}_{3} \mathrm{O}_{4}, \mathrm{MnO}_{2}, \mathrm{Fe}_{2} \mathrm{O}_{3}, \mathrm{Fe}_{3} \mathrm{O}_{4}$, $\mathrm{NaAsO}_{2}$, and $\mathrm{Na}_{3} \mathrm{AsO}_{4} \cdot 12 \mathrm{H}_{2} \mathrm{O}$ (purchased from Sigma-Aldrich, USA or URCHEM, China) were simultaneously analyzed for use as model spectra to assist interpretation of spectra of BMO, Fe oxide, BFMO, and their As adsorption samples. Samples were measured in transmission or fluorescence mode (used for As analysis due to its low concentration) at room temperature on wiggler beamline 1W1B of BSRF. The Lytle detector was used. The beam spot was focused to $2 \times 2 \mathrm{~mm}^{2}$ by the toroidal mirror. A fixed-exit Si ( $\left.\begin{array}{lll}1 & 1 & 1\end{array}\right)$ double crystal monochromator was used and the harmonic content of the monochrome beam was rejected by detuning the double crystal monochromator. An energy range of $-200-1000 \mathrm{eV}$ from the K-edge of Mn, Fe, and As was used for EXAFS data collection. Standard EXAFS data reduction procedures were carried out using the program package IFEFFIT (Newville, 2001). The $k^{3}$-weighted $\chi(k)$ was Fourier-transformed into $R$ space in the $k$ ranges of 2.6-11.0 $\AA^{-1}$ for Fe K, 2.8-11.0 $\AA^{-1}$ for Mn K, and 2.4-12.4 $\AA^{-1}$ for As $\mathrm{K}$ with a Hanning function window. Shell fitting was adopted for fitting the Fourier-transformed $k^{3}$-weighted (R space) $\mathrm{Mn}, \mathrm{Fe}$, and As K-edge EXAFS spectra. The goodness of fit was evaluated by $R$ factor minimization.

\section{Results}

\subsection{In situ formation of BMO by Pseudomonas sp. QJX-1}

The crucial step of BFMO formation is the generation of BMO by Pseudomonas sp. QJX-1. So, the characteristics of Mn(II) oxidation by QJX-1 under the optimum temperature $\left(30^{\circ} \mathrm{C}\right)$ and $\mathrm{pH}(7.5)$ were investigated, as shown in Supplementary Fig. S1. The results showed that QJX-1 catalyzed the slow transformation of $\mathrm{Mn}$ (II) in the logarithmic growth phase. However, after the logarithmic growth phase and during the stagnant growth phase, Mn(II) was oxidized rapidly. Meanwhile, a brownish black precipitate (i.e., BMO) was produced.

\subsection{In situ formation of BFMO and its capacity for As removal}

Different concentrations of Fe(II) were added to the PYG media containing $\mathrm{Mn}(\mathrm{II})$ and As species, and $\mathrm{OJX}-1$ was subsequently added. In the initial phase of the experiment, due to the rotation, the $\mathrm{Fe}(\mathrm{II})$ ions in the media had sufficient contact with oxygen. Therefore, it was observed that the dark yellow precipitation of Fe oxide occurred within minutes. Then, the BMO was produced by QJX-1 and mixed with Fe oxide to form the BFMO. Chemical analysis of $\mathrm{Fe}(\mathrm{II})$ and $\mathrm{Mn}$ (II) oxidation (Fig. S2) revealed that more than $95 \%$ of $\mathrm{Fe}(\mathrm{II})$ and $\mathrm{Mn}$ (II) were oxidized, except in the media containing $\mathrm{As}(\mathrm{III})$ or $\mathrm{As}(\mathrm{V})$ at a 1:9 $\mathrm{Mn}(\mathrm{II}) / \mathrm{Fe}(\mathrm{II})$ ratio. Fig. 2 shows that the total As removal increased along with the increase of $\mathrm{Fe}(\mathrm{II})$ concentration, implying that Fe oxide plays a dominant role in As removal. In general, $\mathrm{As}(\mathrm{V})$ removal by the BFMO was better than As(III) removal. The optimum $\mathrm{Mn}(\mathrm{II}) / \mathrm{Fe}(\mathrm{II})$ ratio for As removal was determined to be approximately $1: 3(\mathrm{~mol} / \mathrm{mol})$.

\subsection{Oxidation and adsorption of As species by the BMO, Fe oxide, and BFMO formed in situ}

The oxidation and adsorption characteristics of As species among the BFMO formed in situ (1:3 $\mathrm{Mn}(\mathrm{II}) / \mathrm{Fe}(\mathrm{II})$ ratio), BMO, and Fe oxide were compared in order to identify the respective roles of the BMO and Fe oxide parts in the BFMO. In all reaction systems, the buffers used in the culture media ensured little $\mathrm{pH}$ variation, from an initial $\mathrm{pH}$ of 7.50 to $7.33-7.54$ (Table S1) at the end of the experiment. Therefore, the chemical precipitation of $\mathrm{Mn}$ and $\mathrm{Fe}$ oxides induced by alkaline changes were excluded, and $\mathrm{Mn}$ (II) oxidation and $\mathrm{Fe}(\mathrm{II})$ oxidation were attributed to the biological role of $\mathrm{QJX}-1$ and the chemical role of oxygen, respectively. Fig. 3a-b shows the formation of BMO and its chemical role on $\mathrm{As}(\mathrm{III} \& \mathrm{~V})$. The results from the media containing only $\mathrm{QJX}-1$ and As species (denoted as control in the figure) demonstrated that QJX-1 had negligible effects on the oxidation and adsorption of As species. Hence, $\mathrm{As}$ (III) oxidation (i.e., $97.57 \pm 0.62 \%$ of $\mathrm{As}(\mathrm{III})$ was oxidized to $\mathrm{As}(\mathrm{V})$ within $48 \mathrm{~h})$ in the media containing $\mathrm{QJX}-1, \mathrm{Mn}(\mathrm{II})$, and $\mathrm{As}(\mathrm{III})$ was only attributed to the BMO formed in situ (Fig. 3a). However, only small portions of $\mathrm{As}(\mathrm{III})$ and $\mathrm{As}(\mathrm{V})$ were adsorbed on the surface of the formed BMO ( $<5 \%$ ) (Fig. $3 a-b)$. In contrast to the BMO, Fe oxide formed in situ could rapidly (within the minute scale) adsorb $\mathrm{As}(\mathrm{III})$ or $\mathrm{As}(\mathrm{V})$ on its surface (higher than $92 \%$ within $1 \mathrm{~h}$ ) (Fig. 3c-d). The BFMO formed in situ integrated the chemical characteristics of the BMO and Fe oxide; it could not only oxidize but also adsorb the As species (Fig. $3 e-f$ ). It was remarkable that during $\mathrm{Mn}(\mathrm{II})$ oxidation (later than the chemical oxidation of $\mathrm{Fe}(\mathrm{II})$ ), the formed BMO could further oxidize the remaining $\mathrm{Fe}(\mathrm{II})$ in solution to Fe oxide. Moreover, the newly formed Fe oxide was able to adsorb As again, resulting in a decrease of the total As during the experiment.

\subsection{Variation of $\zeta$-potential and particle size}

The variations of $\zeta$-potential during the formation of BMO, Fe oxide, and BFMO as well as their adsorption of As species were measured (Fig. 4). The presence of lipopolysaccharides on the Gram-negative bacterial surface provides negatively charged areas for absorbing cationic species (Yang et al., 2015). Hence, the $\zeta$-potential decreased rapidly with the fast growth of QJX-1. The presence of $\mathrm{Mn}$ (II) increased the $\zeta$-potential of system, probably due to that bacteria adsorbed some Mn(II) on the surface. When As species were introduced, $\mathrm{As}(\mathrm{III})$ existed primarily as $\mathrm{H}_{3} \mathrm{AsO}_{3}^{0}$, an uncharged species, and $\mathrm{As}(\mathrm{V})$ was present mainly as $\mathrm{HAsO}_{4}^{2-}$ and smaller amounts of $\mathrm{H}_{2} \mathrm{AsO}_{4}^{-}$which led to a small decrease of the $\zeta$-potential. When adding $\mathrm{Fe}(\mathrm{II})$ to the media, along with the formation of $\mathrm{Fe}$ 


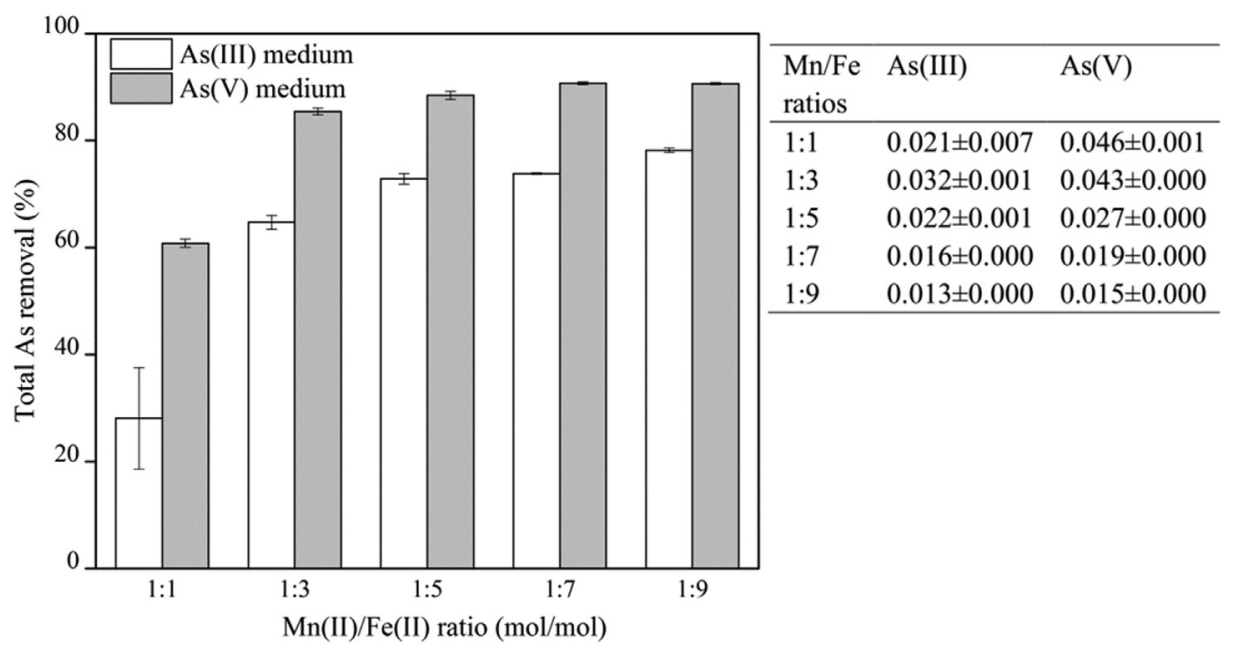

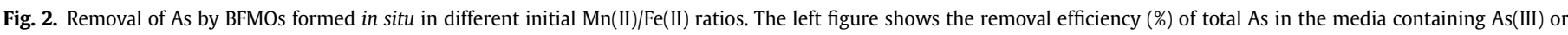

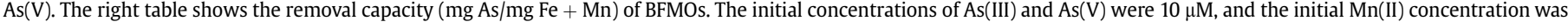

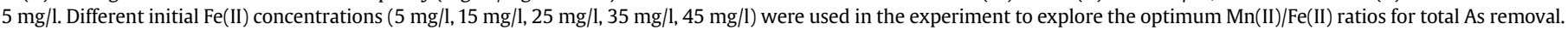
Samples were collected at $72 \mathrm{~h}$. Data points represent the mean value (three replicates) \pm standard deviation.

oxide and occurrence of adsorption, the $\zeta$-potential decreased to the same level as media containing bacteria alone. Further, when the BMO was produced, the $\zeta$-potential value had a significant increase due to the formation of $\mathrm{MnO}_{\mathrm{x}}$ on the bacterial surface.

During the formation of the BMO and Fe oxide separately as well as the BFMO, the suspended particle sizes of each of them all exhibited a gradient increase against the reaction time (before precipitation) (Fig. S3). The maximum suspended BFMO size $(370-400 \mathrm{~nm})$ was between those of the BMO $(700-800 \mathrm{~nm})$ and Fe oxide $(330 \mathrm{~nm})$.

\subsection{TEM, FE-SEM/EDX, and XRD analysis of BMO, Fe oxide, and BFMO}

TEM (Fig. S4) and SEM (Fig. S5) analyses of the formed BMO, Fe oxide, and BFMO precipitates (72 h) show they all had irregular morphology. In general, the sizes of precipitates (in $\mu \mathrm{m}$ scale) were $\mathrm{BMO}>\mathrm{BFMO}>\mathrm{Fe}$ oxide, which is consistent with the comparison of their suspended particle sizes (Fig. S3). EDX results (Fig. S5) indicate that the formed BFMO was not a homogenous compound as Fe/Mn ratios varied in different parts of BFMO. For XRD analysis, the pattern of BMO showed (Fig. 5) that two reflections at $2.46 \AA$ and $1.41 \AA$ ( $d$ spacing) appeared, which were attributed to the (100) and (110) crystal planes of $\delta-\mathrm{MnO}_{2}$ or birnessite consisting of discrete layers or poorly ordered stacking of adjacent layers, respectively (Brock et al., 1999; Tu et al., 2014). Six reflections in XRD pattern of Fe oxide were identical to those of the lepidocrocite (00-044-1415, PDF number) and similar to other FeOOH standards, demonstrating Fe oxide formed in situ was FeOOH. The BMFO sample only displays three weak reflections (belonged to the BMO part) in the XRD profile, suggesting its poor crystallinity.

\subsection{XANES and EXAFS analysis}

The valence states and coordinating atoms of Fe, Mn, and As in the solid phases of the BFMO, BMO, and Fe oxide were investigated using K-edge XANES and EXAFS analyses. Fig. 6a shows that both the pre-edge peaks and the post-edge regions of Mn K XANES in the BFMO and BMO are almost identical to those of the $\mathrm{MnO}_{2}$ reference samples, with a maximum absorbance at $6561 \mathrm{eV}$, demonstrating that $\mathrm{Mn}$ is primarily in the +IV state in the BFMO and BMO. The adsorption edge energies of Fe species in the BFMO and $\mathrm{Fe}$ oxide were between the values of $\mathrm{Fe}_{3} \mathrm{O}_{4}$ and $\mathrm{Fe}_{2} \mathrm{O}_{3}$, suggesting the mixed valence state of the Fe species due to incomplete Fe(II) oxidation in the BFMO and Fe oxide. Fig. $6 \mathrm{c}$ shows that the As K XANES spectra in the As-adsorbed BFMO and BMO are identical to that of $\mathrm{Na}_{3} \mathrm{AsO}_{4}$, demonstrating that $\mathrm{As}(\mathrm{III})$ adsorbed on the surface of BMO and BFMO was completely oxidized to $\mathrm{As}(\mathrm{V})$. However, for the As(III)-Fe oxide sample, the maximum absorbance energy was between those of $\mathrm{Na}_{3} \mathrm{AsO}_{4}$ and $\mathrm{NaAsO}_{2}$, suggesting that only a portion of $\mathrm{As}(\mathrm{III})$ was oxidized to $\mathrm{As}(\mathrm{V})$ on the Fe oxide surface.

The $k^{3}$-weighted and Fourier-transformed $k^{3}$-weighted ( $\mathrm{R}$ space) $\mathrm{Mn}, \mathrm{Fe}$, and As K-edge EXAFS spectra are shown in Fig. S6 and Fig. 7, respectively. Only the first shell (As-O) for the As Kedge spectra and the first and second shells for the Mn and Fe Kedge spectra were fitted due to the small scattering effect of photoelectrons of As coordination (Fig. 7). Good curve-fitting degrees ( $\mathrm{R}$ factor $\leq 0.012$, Tables $\mathrm{S} 2-\mathrm{S} 4$ ) were obtained between experimental data and theoretical results. The coordination numbers and bond distances are also shown in Tables S2-S4. According to the $k^{3}$-weighted Mn K-edge spectra (Fig. S6a), the spectrum of BMO is similar to that of $\mathrm{MnO}_{2}$ reference sample. The occurrence of two distinct feature peaks at $8 \AA^{-1}$ and $9 \AA^{-1}$ suggests that the BMO structure is a hexagonal birnessite (Butterfield et al., 2013; Webb et al., 2005). The Fe-Fe interatomic distance in Fe-containing samples was approximately 3.06 (Table S3), corresponding to edge sharing between $\mathrm{Fe}^{\mathrm{III}} \mathrm{O}_{6}$ octahedra (Manceau and Combes, 1988; Thoral et al., 2005). The As-O bond distance of the first shell was found to be $1.68-1.71 \AA$ for $\mathrm{As}(\mathrm{III} \& \mathrm{~V})$ adsorbed by the BMO or BFMO, whereas it increased to $1.75 \AA$ for the As(III)FeOOH sample (Table S4). This finding confirmed the oxidation of As(III) in the BMO or BFMO (Zhang et al., 2014). The similarity of the Fe and Mn K-edge spectra and bond distances of the first and second coordination shells between before and after $\mathrm{As}(\mathrm{III} \& \mathrm{~V})$ adsorption suggested that the BMO, BFMO, and $\mathrm{FeOOH}$ maintained their local structures during the oxidation or adsorption process. Due to the low concentration of As in the reaction systems, obvious peaks representing the As-O-Fe or As-O-Mn bond in the As K-edge EXAFS spectra were not identified (Fig. 6c and Fig. S6c). However, by comparing the BFMO structure with those of synthetic Fe-Mn oxides (Zhang et al., 2014) and other $\mathrm{MnO}_{2}$ (Manning et al., 2002) and FeOOH samples (Manning et al., 1998; Sherman and Randall, 2003), it can be speculated that the As(III)- and 


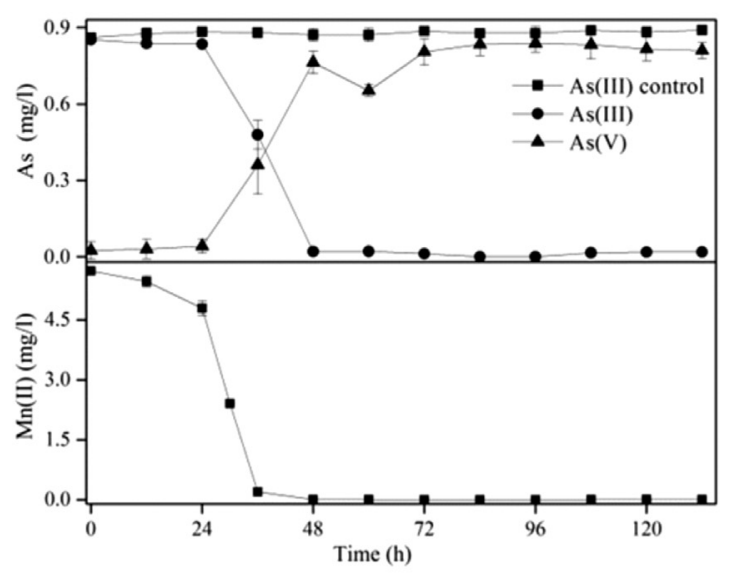

(a)

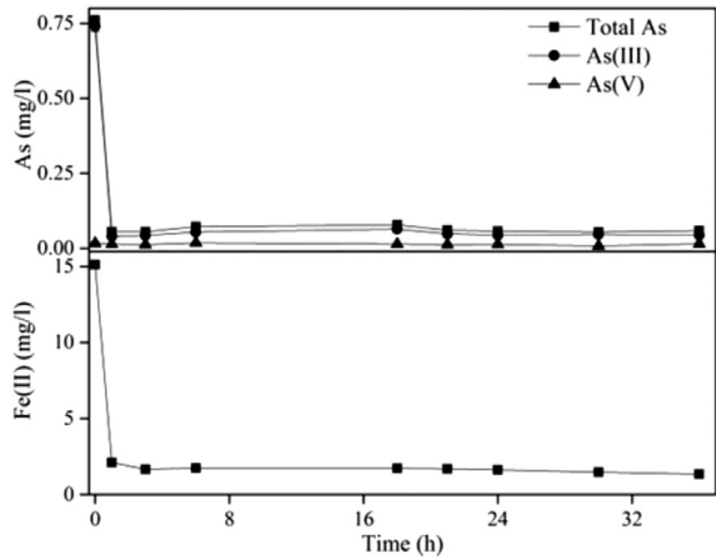

(c)

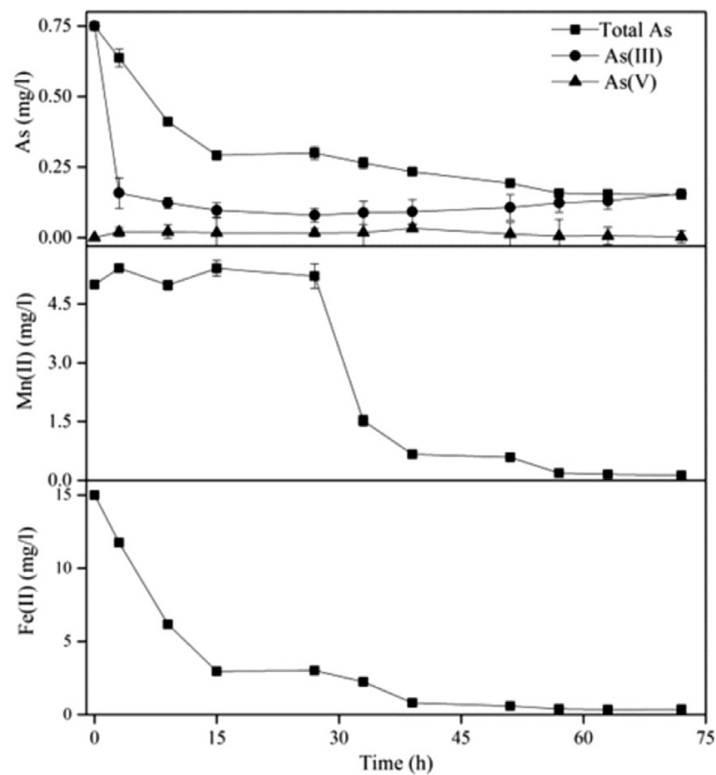

(e)

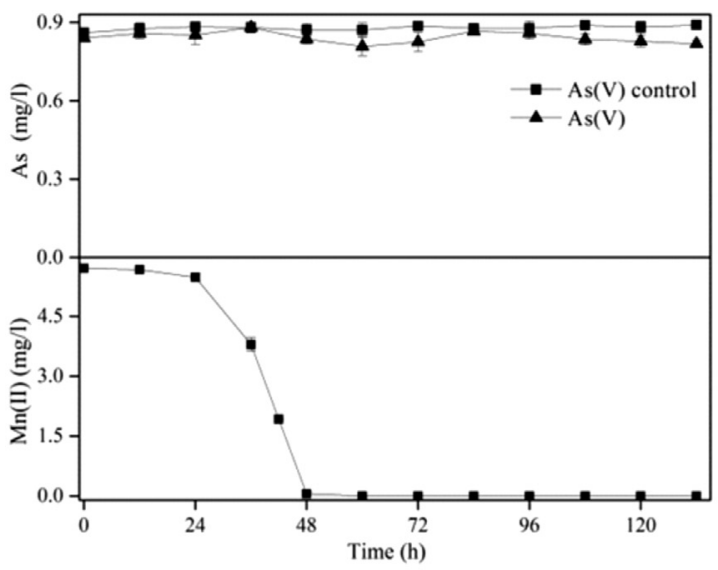

(b)

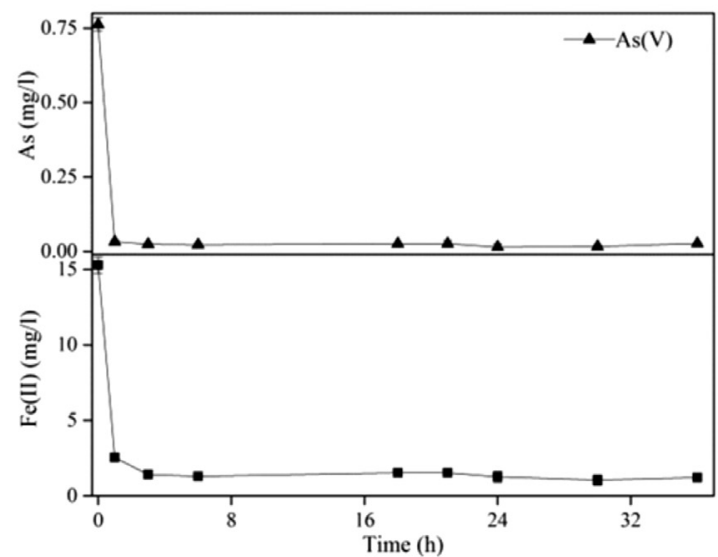

(d)

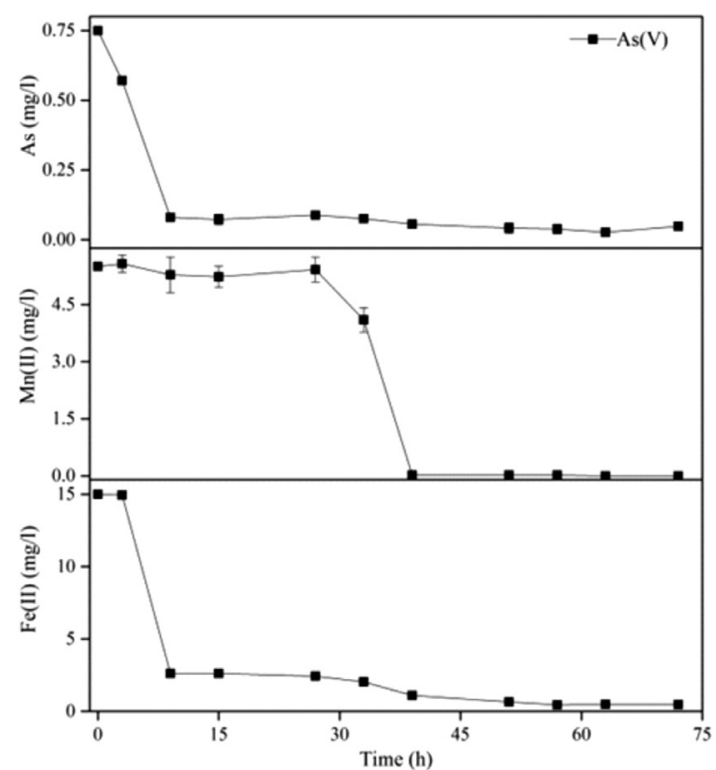

(f)

Fig. 3. Oxidation and adsorption of As species in different reaction systems. (a) As(III)+Mn(II)+QJX-1; (b) As(V)+Mn(II) $+\mathrm{QJX}-1$; (c) $\mathrm{As}(\mathrm{III})+\mathrm{Fe}(\mathrm{II})+\mathrm{QJX}-1$; (d) $\mathrm{As}(\mathrm{V})+\mathrm{Fe}(\mathrm{II})+\mathrm{QJX}-1$; (e) $\mathrm{As}(\mathrm{III})+\mathrm{Fe}(\mathrm{II})+\mathrm{Mn}(\mathrm{II})+\mathrm{QJX}-1$; (f) $\mathrm{As}(\mathrm{V})+\mathrm{Fe}(\mathrm{II})+\mathrm{Mn}(\mathrm{II})+\mathrm{QJX}-1$. Control: the media containing only $\mathrm{OJX}-1$ and As species. Data points represent the mean value (three replicates) \pm standard deviation. 


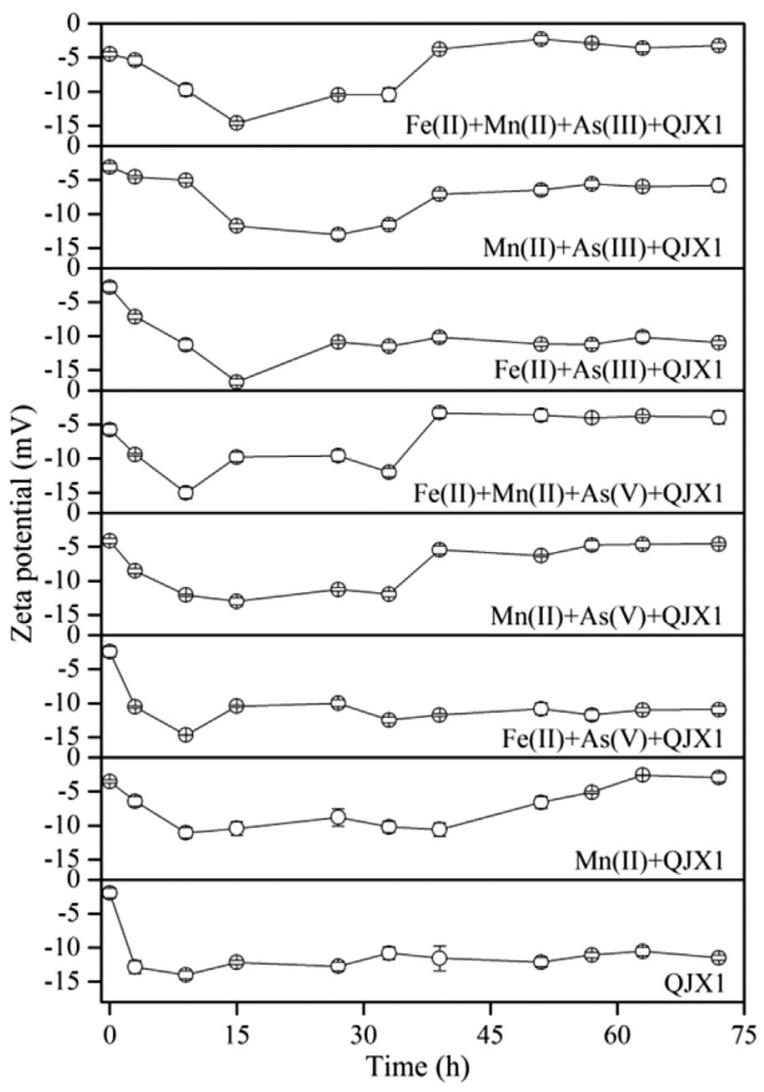

Fig. 4. ל-Potential variation against time in different reaction systems. Data points represent the mean value (three replicates) \pm standard deviation.

As(V)-adsorbed BFMO samples were inner-sphere bidentate binuclear corner-sharing As-BFMO complexes.

\section{Discussion}

\subsection{BFMO formation}

$\mathrm{Fe}(\mathrm{II})$ was rapidly oxidized to a hydrous ferric oxide in the aerated environment due to the chemical reaction with oxygen. However, the formation of BMO exhibited a lag time, even after the log phase of bacterial growth (Fig. S1). The inconsistency of bacterial growth and the $\mathrm{Mn}$ (II) oxidation rate indicate that QJX-1 exerted an indirect role on $\mathrm{Mn}(\mathrm{II})$ oxidation, i.e., superoxide was formed first by the bacteria and then superoxide oxidized $\mathrm{Mn}$ (II) to the BMO (Hansel et al., 2012; Learman et al., 2013). Hence, the Fe oxide and BMO parts of the BFMO were formed in turn, and then they were mixed to form the BFMO. It seems that the BMO and Fe oxide parts in BFMO were not chemically bound because their structures were not changed after mixing (Fig. S6). Based on the results of XRD and EXAFS analyses, the BMO formation at circumneutral $\mathrm{pH}$ resulted in a highly disordered layered phyllomanganate phase with hexagonal symmetry, which is similar to other BMOs (Bargar et al., 2000, 2009). The Fe oxide part (identified as $\mathrm{FeOOH}$ ) had octahedral $\mathrm{FeO}_{6}$ and showed a high affinity for As(III\&V) adsorption.

\subsection{Mechanism for As(III) oxidation and adsorption by BFMO formed in situ}

Based on our results, we obtained a clear picture for the As(III) oxidation and adsorption processes and proposed the following

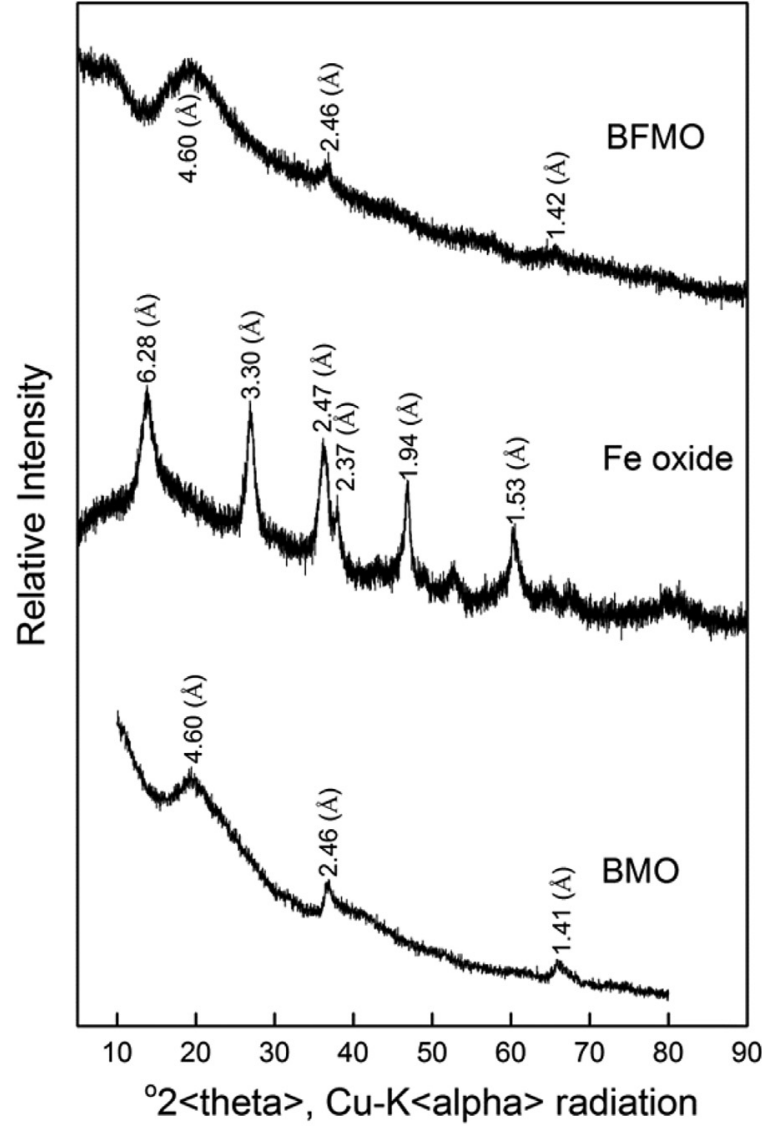

Fig. 5. X-ray diffraction patterns of BMO, Fe oxide, and BFMO.

mechanism: As(III) is first adsorbed on the surface of Fe oxide (FeOOH) formed in situ. The $\mathrm{FeOOH}$ by itself has a small oxidation ability and some of $\mathrm{As}(\mathrm{III})$ ions are oxidized to $\mathrm{As}(\mathrm{V})$ on the surface of $\mathrm{FeOOH}$ precipitates (Fig. 6), As(III) in the aqueous phase is not oxidized (Fig. 3c). Subsequently, the adsorbed $\mathrm{As}$ (III) on the $\mathrm{FeOOH}$ surface and the As(III) ions in solution are then oxidized by the formed BMO. The BMO can also oxidize the remaining $\mathrm{Fe}(\mathrm{II})$ in solution. The formation of new Fe oxide would further adsorb the $\mathrm{As}(\mathrm{V})$ ions remain. Taken together, we conclude that the BMO part in the BFMO is mainly responsible for As(III) oxidation and the FeOOH part dominates As adsorption (Figs. 3 and 6). In comparison with the BMO and $\mathrm{FeOOH}$ separately, the formed BFMO had an oxidation and adsorption ability for $\mathrm{As}(\mathrm{III})$ that was between the individual parts due to the antagonistic role (occupying oxidation or adsorption sites for each other) between Fe oxide and the BMO.

Previous studies found that BMOs can efficiently adsorb various metal cations (e.g., $\mathrm{Pb}, \mathrm{Cd}, \mathrm{Zn}$, and $\mathrm{Ni}$ ) (Nelson et al., 2002; Wang et al., 2009; Zhou et al., 2015). In our study the formed BMO did not significantly adsorb As (Fig. 2a-b) probably due to that As is an oxyanion. Moreover, we did not observe a shift in As adsorptiondesorption during the reaction of the BMO and As species, which has been reported previously in a Mn-oxidizing fungus study (Tani et al., 2004). This discrepancy was probably due to the facts that both the BMO surface and $\mathrm{As}(\mathrm{V})$ have negative charges (Fig. 4) and the charge repulsion led to a weak adsorption.

\subsection{Comparison between the BFMO and synthetic Fe-Mn oxides}

Recently, synthetic Fe-Mn oxides have been demonstrated to remove organics (Liu et al., 2012), inorganics (Peng et al., 2009), and 


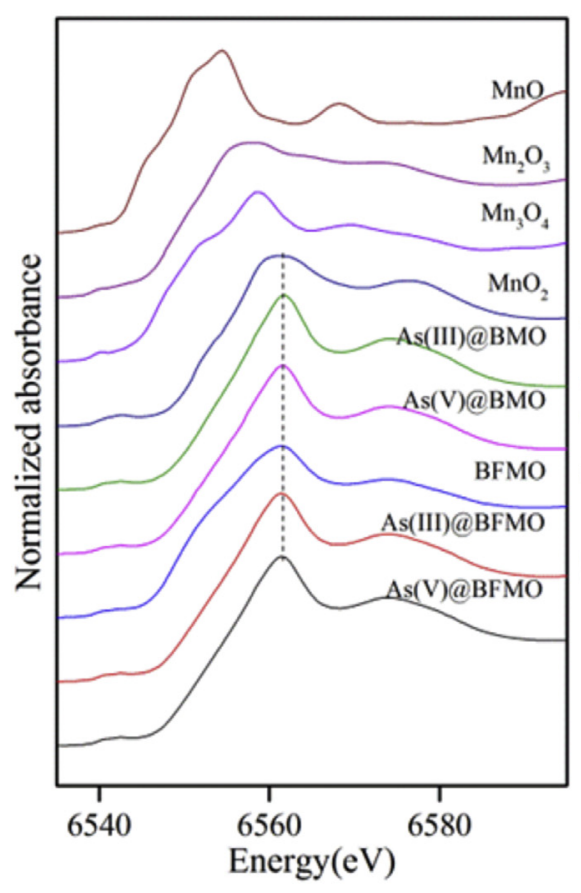

(a)

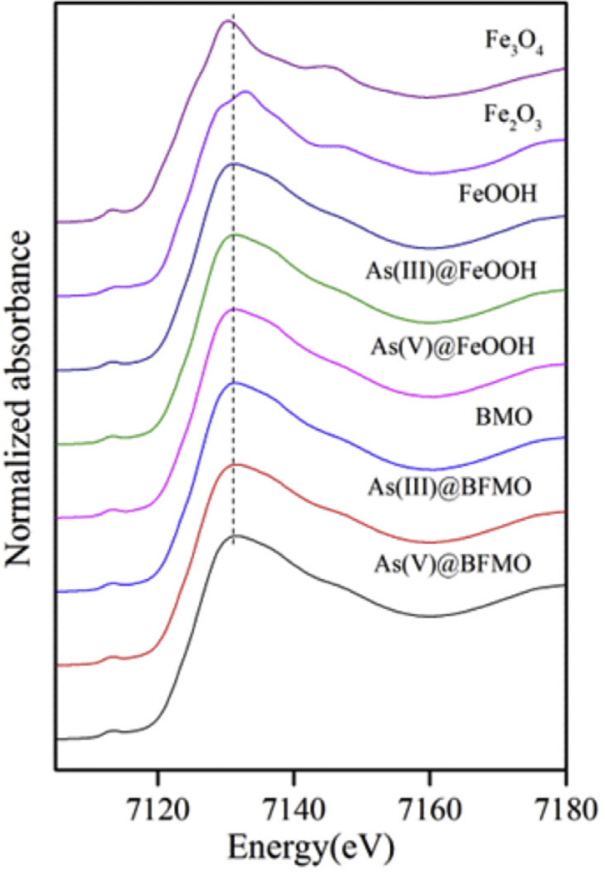

(b)

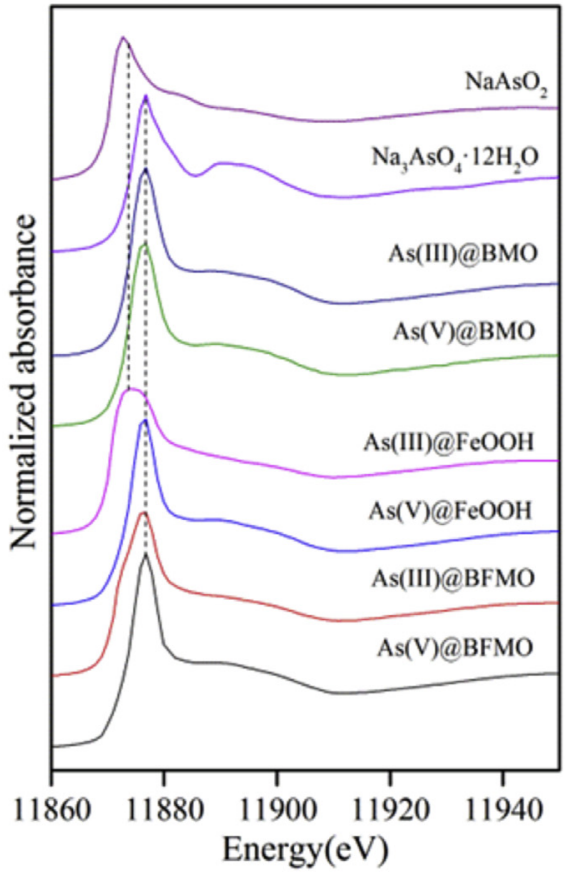

(c)

Fig. 6. Normalized XANES of K edge in (a) Mn-containing, (b) Fe-containing, and (c) As-adsorbed samples and reference samples.

metalloids (Zhang et al., 2007) effectively. Here, we compared the characteristics of the BFMO and the synthetic Fe-Mn oxides studied previously (Shan and Tong, 2013; Zhang et al., 2014). The similarities between the two complexes are as follows: (i) they are both formed from a mixture of Mn oxide and Fe oxide precipitation (ii) the optimum $\mathrm{Mn} / \mathrm{Fe}$ ratio for As adsorption is approximately $1: 3$ ( $\mathrm{mol} / \mathrm{mol}$ ); and (iii) the mechanisms of oxidation and adsorption are identical, i.e., the Mn oxide part controls oxidation and the Fe oxide part dominates adsorption. Due to the differences in the structure of Mn oxide part (the Mn oxide in synthetic Fe-Mn oxides was identified as $\mathrm{MnO}_{\mathrm{x}}, 1.5<\mathrm{x}<2$ (Zhang et al., 2014)) and the presence/absence of microbes, the BFMO and synthetic Fe-Mn oxides have significant differences in oxidation and adsorption. The dissimilarities are as follows: (i) the BFMO prefers to adsorb $\mathrm{As}(\mathrm{V})$ over As(III), but synthetic Fe-Mn oxides have the opposite preference; (ii) synthetic Fe-Mn oxides have a greater adsorption capacity than the BFMO because the BFMO contains Mn-oxidizing bacteria (Mn oxide particles form on the bacterial surface (Jones et al., 2012)), and these bacteria occupy some adsorption sites of $\mathrm{FeOOH}$; (iii) although both the BFMO and synthetic Fe-Mn oxides release Mn(II) during the oxidation of As(III), in the synthetic Fe-Mn oxide system, the released $\mathrm{Mn}(\mathrm{II})$ is retained in the water. But in the BFMO system, the released $\mathrm{Mn}(\mathrm{II})$ is re-oxidized by the Mnoxidizing bacteria. With this cycle, the $\mathrm{Mn}(\mathrm{II})$ can be eliminated from water. Also due to that BMO could oxidize Fe(II), the Fe(II) would not be retained in water in case the reduction reaction of $\mathrm{Fe}$ oxide occurs.

\subsection{Implication for $\mathrm{Mn}, \mathrm{Fe}$, and As remediation}

In natural aquatic ecosystems, Mn oxide often exists with $\mathrm{Fe}$ oxide, and they form Fe-Mn oxides together in the sediment (Zhang et al., 2008). Mn-oxidizing microbes play an essential role in the formation of Fe-Mn oxides as microbial Mn oxidation is the dominant pathway in natural Mn oxidation (He et al., 2008). Hence, according to our study, BFMOs may be a critical factor in the natural remediation of As-contaminated water. In addition, high concentrations of $\mathrm{Fe}(\mathrm{II})$ and $\mathrm{Mn}$ (II) may occur together in As-contaminated groundwater. In conventional groundwater treatment plants, if the presence of Mn-oxidizing microbes, the BMFO could form on the surface of sand filter materials (Bai et al., 2013). The formed BFMO plays a certain role in As removal, and, at the same time, $\mathrm{Fe}(\mathrm{II})$ and $\mathrm{Mn}$ (II) would not be released. Based on our findings, we propose the development of two strategies to improve groundwater treatment: (i) using bioaugmentation techniques (Bai et al., 2011) (adding some harmless Mn-oxidizing microorganisms to the sand filter); and (ii) using synthetic Fe-Mn oxides as a filter material instead of the sand filter as well as adding harmless Mn-oxidizing microorganisms to the filter in order to prevent the release of $\mathrm{Mn}(\mathrm{II})$ and $\mathrm{Fe}(\mathrm{II})$ due to the reduction reaction. Compared with current treatment methods, e.g., coagulation/flocculation, iron exchange, adsorption, and chemical redox (Ungureanu et al., 2015), our proposed methods based on BFMO formation would be costeffective, i.e. low cost with adding bacteria, simultaneous removal of $\mathrm{Fe}(\mathrm{II}), \mathrm{Mn}(\mathrm{II})$ and other pollutants, and without second pollution (BFMOs would be retained in the filter and the released bacteria (in case) can be killed by the following UV process).

\section{Conclusions}

In this study, the proposed hypothesis that the BFMO formed in situ could oxidize and adsorb As species was verified. In addition, the underlying mechanism for As oxidation and adsorption by the BFMO was investigated. There were three main outcomes from the study: (i) BFMO formation occurred through precipitation, i.e., $\mathrm{Fe}(\mathrm{II})$ chemical oxidation to $\mathrm{FeOOH}$ and $\mathrm{Mn}$ (II) biological oxidation to $\mathrm{MnO}_{2}$; the BFMO formed in situ preferred to adsorb $\mathrm{As}(\mathrm{V})$ rather than As(III); in general, the optimum initial $\mathrm{Mn}(\mathrm{II})$ : $\mathrm{Fe}(\mathrm{II})$ ratio for As adsorption was approximately $1: 3(\mathrm{~mol} / \mathrm{mol})$; (ii) in the BFMO, the $\mathrm{BMO}$ part was mainly responsible for $\mathrm{As}(\mathrm{III})$ oxidation (a small 


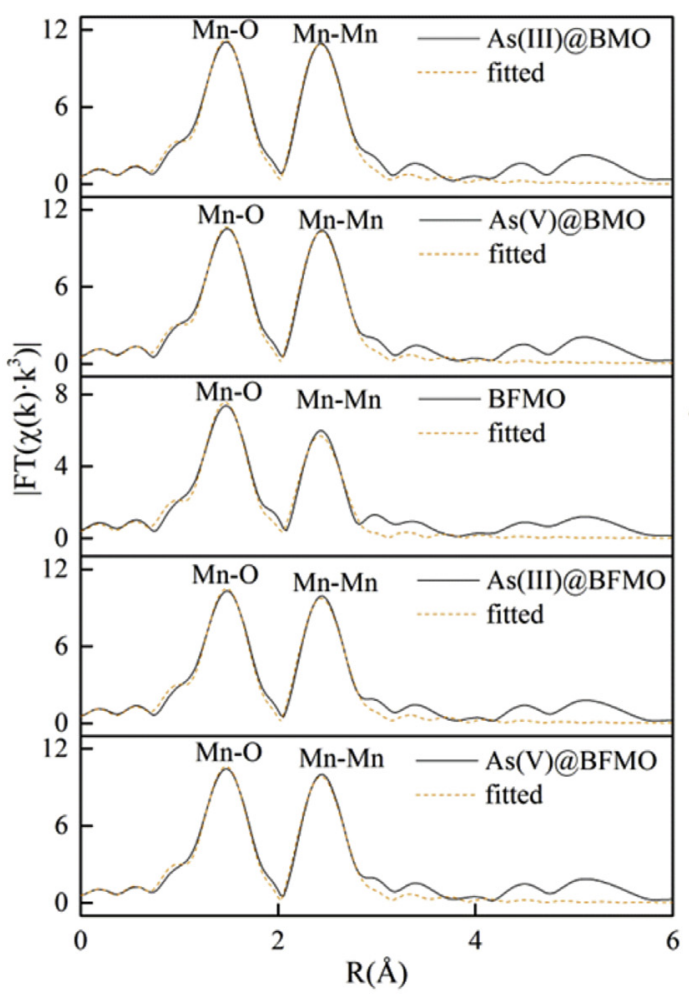

(a)

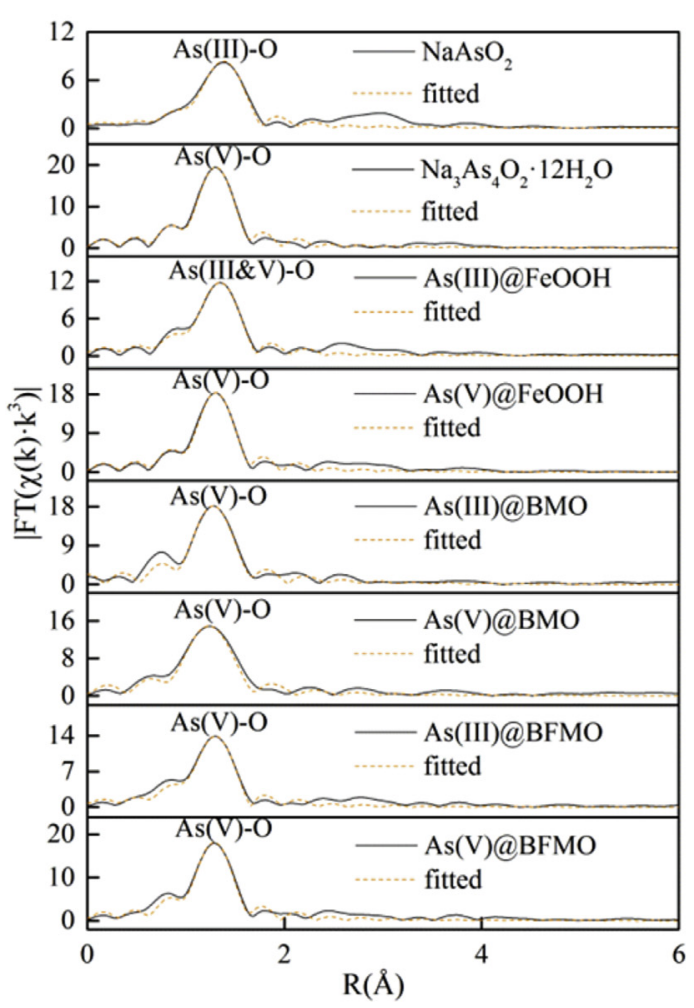

(c)

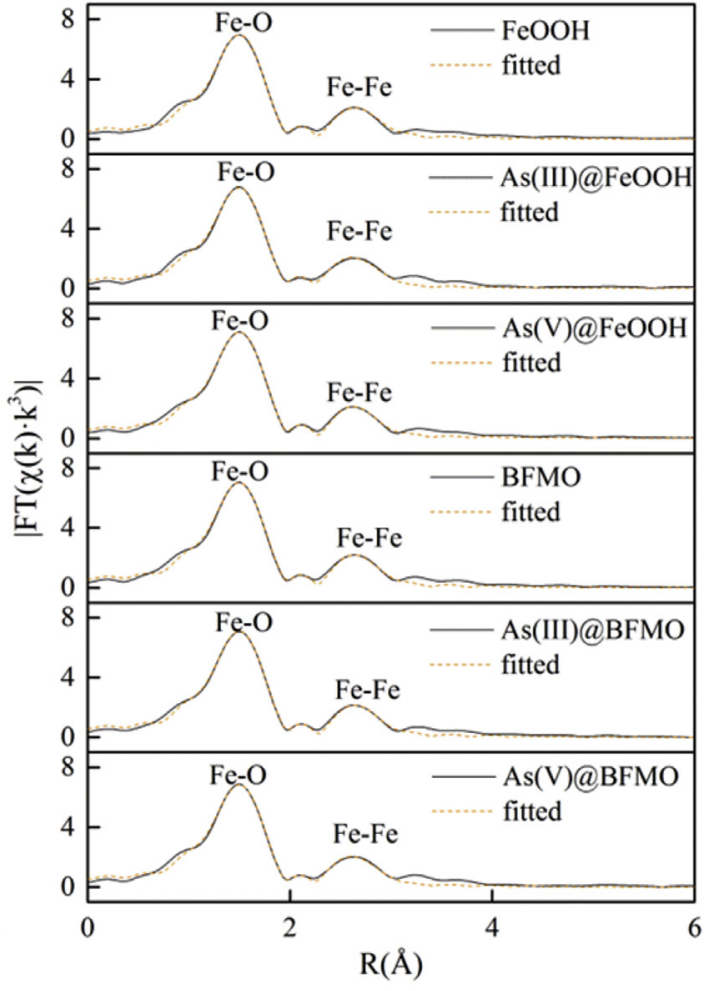

(b)

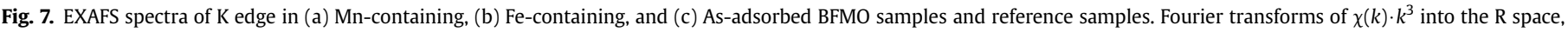
where the red dashed lines denote the curve-fitting results. 
contribution from $\mathrm{FeOOH}$ ), and the $\mathrm{FeOOH}$ part dominated As adsorption. It was most likely that the As(III\&V)-BFMO complex was an inner-sphere bidentate binuclear corner-sharing (bridged) complex; (iii) As oxidation by synthetic Fe-Mn oxides may release $\mathrm{Mn}(\mathrm{II})$ and $\mathrm{Fe}(\mathrm{II})$ ions. However, in the BFMO, the released $\mathrm{Mn}$ (II) could be re-oxidized by bacteria and the BMO (re)generated in situ could further oxidize As(III) and Fe(II) ions. Therefore, these reactions form a cycle, which can eliminate $\mathrm{Fe}(\mathrm{II}), \mathrm{Mn}(\mathrm{II})$, and As species from the water simultaneously.

Hence, according to our study, the BFMO may be a critical factor in the natural remediation of As-contaminated water as well as in the purification of groundwater for drinking (sand filter process). Furthermore, when groundwater contains high concentrations of $\mathrm{Mn}(\mathrm{II}), \mathrm{Fe}(\mathrm{II})$, and As (III or V), we may use a bioaugmentation technique to eliminate or decrease the above pollutants.

\section{Acknowledgments}

We warmly thank Lirong Zheng from the Beijing Synchrotron Radiation Facility for his kind assistance in XAS analysis. This study was supported by a major program (51290282) and a general program (51578537) granted by the National Natural Science Foundation of China, a special fund (13Z03ESPCT) granted by the Key Laboratory of Drinking Water Science and Technology.

\section{Appendix A. Supplementary data}

Supplementary data related to this article can be found at http:// dx.doi.org/10.1016/j.watres.2016.03.068.

\section{References}

Adams, L.F., Ghiorse, W.C., 1985. Influence of manganese on growth of a sheathless strain of Leptothrix-Discophora. Appl. Environ. Microbiol. 49 (3), 556-562.

Bai, Y.H., Liu, R.P., Liang, J.S., Qu, J.H., 2013. Integrated metagenomic and physiochemical analyses to evaluate the potential role of microbes in the sand filter of a drinking water treatment system. Plos One 8 (4), e61011.

Bai, Y.H., Sun, Q.H., Sun, R.H., Wen, D.H., Tang, X.Y., 2011. Bioaugmentation and adsorption treatment of coking wastewater containing pyridine and quinoline using zeolite-biological aerated filters. Environ. Sci. Technol. 45 (5), 1940-1948.

Bargar, J.R., Fuller, C.C., Marcus, M.A., Brearley, A.J., De la Rosa, M.P., Webb, S.M. Caldwell, W.A., 2009. Structural characterization of terrestrial microbial Mn oxides from Pinal Creek, AZ. Geochim. Cosmochim. Ac 73 (4), 889-910.

Bargar, J.R., Tebo, B.M., Villinski, J.E., 2000. In situ characterization of $\mathrm{Mn}(\mathrm{II})$ oxidation by spores of the marine Bacillus sp. strain SG-1. Geochim. Cosmochim. Ac 64 (16), 2775-2778.

Berg, M., Luzi, S., Trang, P.T.K., Viet, P.H., Giger, W., Stuben, D., 2006. Arsenic remova from groundwater by household sand filters: comparative field study, mode calculations, and health benefits. Environ. Sci. Technol 40 (17) 5567-5573.

Brock, S.L., Sanabria, M., Suib, S.L., Urban, V., Thiyagarajan, P., Potter, D.I., 1999. Particle size control and self-assembly processes in novel colloids of nanocrystalline manganese oxide. J. Phys. Chem. B 103 (35), 7416-7428.

Butterfield, C.N., Soldatova, A.V., Lee, S.W., Spiro, T.G., Tebo, B.M., 2013. Mn(II, III) oxidation and $\mathrm{MnO}_{2}$ mineralization by an expressed bacterial multicopper oxidase. Proc. Natl. Acad. Sci. U. S. A. 110 (29), 11731-11735.

Davolos, D., Pietrangeli, B., 2013. A molecular study on bacterial resistance to arsenic-toxicity in surface and underground waters of Latium (Italy). Ecotox. Environ. Safe 96, 1-9.

Faust, A., 1998. Chemistry of Water Treatment. CRC Press.

Gebel, T., 1997. Arsenic and antimony: comparative approach on mechanistic toxicology. Chem. Biol. Interact. 107 (3), 131-144.

Hansel, C.M., Learman, D.R., Voelker, B.M., Vazquez-Rodriguez, A.I., 2011. Formation of manganese oxides by bacterially generated superoxide. Nat. Geosci. 4 95-98.

Hansel, C.M., Zeiner, C.A., Santelli, C.M., Webb, S.M., 2012. Mn(II) oxidation by an ascomycete fungus is linked to superoxide production during asexual reproduction. Proc. Natl. Acad. Sci. U. S. A. 109 (31), 12621-12625.

He, J.Z., Zhang, L.M., Jin, S.S., Zhu, Y.G., Liu, F., 2008. Bacterial communities inside and surrounding soil iron-manganese nodules. Geomicrobiol. J. 25 (1), 14-24.

Huang, L.B., Bai, J.H., Xiao, R., Gao, H.F., Liu, P.P., 2012. Spatial distribution of Fe, Cu, $\mathrm{Mn}$ in the surface water system and their effects on wetland vegetation in the pearl river estuary of China. Clean-Soil Air Water 40 (10), 1085-1092.

Jones, L.C., Lafferty, B.J., Sparks, D.L., 2012. Additive and competitive effects of bacteria and Mn oxides on arsenite oxidation kinetics. Environ. Sci. Technol. 46 (12), 6548-6555.

Kappler, A., Straub, K.L., 2005. Geomicrobiological cycling of iron. Rev. Mineral. Geochem 59, 85-108.

Learman, D.R., Voelker, B.M., Madden, A.S., Hansel, C.M., 2013. Constraints on superoxide mediated formation of manganese oxides. Front. Microbiol. 4, 262.

Liu, H.J., Yang, Y., Kang, J., Fan, M.H., Qu, J.H., 2012. Removal of tetracycline from water by Fe-Mn binary oxide. J. Environ. Sci.-China 24 (2), 242-247.

Manceau, A., Combes, J.M., 1988. Structure of Mn and Fe oxides and oxyhydroxides: a topological approach by EXAFS. Phys. Chem. Miner. 15 (3), 283-295.

Manning, B.A., Fendorf, S.E., Bostick, B., Suarez, D.L., 2002. Arsenic(III) oxidation and arsenic(V) adsorption reactions on synthetic birnessite. Environ. Sci. Technol. 36 (5), 976-981.

Manning, B.A., Fendorf, S.E., Goldberg, S., 1998. Surface structures and stability of arsenic(III) on goethite: spectroscopic evidence for inner-sphere complexes. Environ. Sci. Technol. 32 (16), 2383-2388.

Murray, K.J., Mozafarzadeh, M.L., Tebo, B.M., 2005. Cr(III) oxidation and Cr toxicity in cultures of the manganese(II)-Oxidizing Pseudomonas putida strain GB-1. Geomicrobiol. J. 22 (3-4), 151-159.

Nelson, Y.M., Lion, L.W., Shuler, M.L., Ghiorse, W.C., 2002. Effect of oxide formation mechanisms on lead adsorption by biogenic manganese (hydr)oxides, iron (hydr)oxides, and their mixtures. Environ. Sci. Technol. 36 (3), 421-425.

Newville, M., 2001. IFEFFIT: interactive EXAFS analysis and FEFF fitting. J. Synchrotron Rad. 8, 322-324.

Nishimura, T., Umetsu, Y., 2001. Oxidative precipitation of arsenic(III) with manganese(II) and iron(II) in dilute acidic solution by ozone. Hydrometallurgy 62 (2), 83-92.

Peng, B., Wang, J.Y., Zhang, H.X., Lin, Y.H., Cai, W.B., 2009. A versatile electroless approach to controlled modification of $\mathrm{Sb}$ on Pt surfaces towards efficient electrocatalysis of formic acid. Electrochem. Commun. 11 (4), 831-833.

Postawa, A., Hayes, C., 2013. Best Practice Oguide on the Control of Iron and Manganese in Water Supply. IWA Publishing, London, UK.

Shan, C., Tong, M.P., 2013. Efficient removal of trace arsenite through oxidation and adsorption by magnetic nanoparticles modified with Fe-Mn binary oxide. Water Res. 47 (10), 3411-3421.

Sherman, D.M., Randall, S.R., 2003. Surface complexation of arsenie(V) to iron(III) (hydr)oxides: structural mechanism from ab initio molecular geometries and EXAFS spectroscopy. Geochim. Cosmochim. Ac 67 (22), 4223-4230.

Tani, Y., Miyata, N., Ohashi, M., Ohnuki, T., Seyama, H., Iwahori, K., Soma, M., 2004. Interaction of inorganic arsenic with biogenic manganese oxide produced by a Mn-oxidizing fungus, strain KR21-2. Environ. Sci. Technol. 38 (24), 6618-6624.

Tebo, B.M., Spiro, T.G., Bargar, J.R., Sposito, G., 2010. Bacteriogenic manganese oxides. Accounts Chem. Res. 43 (1), 2-9.

Thoral, S., Rose, J., Garnier, J.M., Van Geen, A., Refait, P., Traverse, A., Fonda, E., Nahon, D., Bottero, J.Y., 2005. XAS study of iron and arsenic speciation during Fe(II) oxidation in the presence of As(III). Environ. Sci. Technol. 39 (24), 9478-9485.

Tu, J.J., Yang, Z.D., Hu, C., Qu, J.H., 2014. Characterization and reactivity of biogenic manganese oxides for ciprofloxacin oxidation. J. Environ. Sci.-China 26 (5), 1154-1161.

Ungureanu, G., Santos, S., Boaventura, R., Botelho, C., 2015. Arsenic and antimony in water and wastewater: overview of removal techniques with special reference to latest advances in adsorption. J. Environ. Manage 151, 326-342.

Viraraghavan, T., Subramanian, K.S., Aruldoss, J.A., 1999. Arsenic in drinking water problems and solutions. Water Sci. Technol. 40 (2), 69-76.

Voegelin, A., Kaegi, R., Berg, M., Nitzsche, K.S., Kappler, A., Lan, V.M., Trang, P.T.K., Gottlicher, J., Steininger, R., 2014. Solid-phase characterisation of an effective household sand filter for As, Fe and Mn removal from groundwater in Vietnam. Environ. Chem. 11 (5), 566-578.

Wang, W.M., Shao, Z.Z., Liu, Y.J., Wang, G.J., 2009. Removal of multi-heavy metals using biogenic manganese oxides generated by a deep-sea sedimentary bacterium - brachybacterium sp. strain Mn32. Microbiology-SGM 155, 1989-1996.

Webb, S.M., Tebo, B.M., Bargat, J.R., 2005. Structural characterization of biogenic Mn oxides produced in seawater by the marine Bacillus sp. strain SG-1. Am. Mineral. 90 (8-9), 1342-1357.

Wu, Y.X., Deng, B.L., Xu, H.F., Konishi, H., 2005. Chromium(III) oxidation coupled with microbially mediated Mn(II) oxidation. Geomicrobiol. J. 22 (3-4), 161-170.

Yang, C., Xie, H., Li, Q.C., Sun, E.J., Su, B.L., 2015. Adherence and interaction of cationic quantum dots on bacterial surfaces. J. Colloid Interf Sci. 450, 388-395.

Zhang, G.S., Liu, F.D., Liu, H.J., Qu, J.H., Liu, R.P., 2014. Respective role of Fe and Mn oxide contents for arsenic sorption in iron and manganese binary oxide: an Xray absorption spectroscopy investigation. Environ. Sci. Technol. 48 (17), $10316-10322$

Zhang, G.S., Qu, J.H., Liu, H.J., Liu, R.P., Wu, R.C., 2007. Preparation and evaluation of a novel Fe-Mn binary oxide adsorbent for effective arsenite removal. Water Res. 41 (9), 1921-1928.

Zhang, L.M., Liu, F., Tan, W.F., Feng, X.H., Zhu, Y.G., He, J., 2008. Microbial DNA extraction and analyses of soil iron-manganese nodules. Soil Biol. Biochem. 40 (6), 1364-1369.

Zhou, D., Kim, D.G., Ko, S.O., 2015. Heavy metal adsorption with biogenic manganese oxides generated by Pseudomonas putida strain MnB1. J. Ind. Eng. Chem. 24, 132-139. 